Egyptian

Orthodontic Journal

\title{
COMPARISON OF LABIAL CORTICOTOMY VS PALATAL CORTICOTOMY DURING EN MASSE RETRACTION WITH MINI SCREWS AS ANCHORAGE UNITS
}

\author{
Walaa E. El.Gemeay ${ }^{1}$, Mohamed A. Nadim², \\ Tamer Abd El Bari Hamed ${ }^{3}$, Tamer M. Bedair ${ }^{4}$, Abbadi A.EL-Kadi ${ }^{5}$ \\ ABSTRACT:
}

Aim: The aim of this study was to evaluate and compare the treatment effects and duration of en-masse retraction combined with labial corticotomy and that with palatal corticotomy using miniscrews as source of anchorage. Methods: Twenty adult patients with bimaxillary or maxillary protrusion requiring orthodontic treatment with upper anterior retraction in the extraction space of first premolars were selected. Patients were divided into two groups; labial corticotomy gruop and palatal corticotomy group, each group consisted of 10 subjects. The retraction time was estimated. Cephalometric radiographs were taken before treatment (T1) and after treatment (T2). Results: There was no significant difference in retraction time between labial and palatal corticotomy groups. Radiographic evaluation showed significant maxillary incisor retraction. Conclusion: The use of corticotomy technique from labial side only could be beneficial for adult patients with difficult surgical access from the palatal side.

1- Assistant Lecturer, Department of Orthodontics, Faculty of Dentistry, Suez Canal University.

2- Assistant Professor, Department of Orthodontics, Faculty of Dentistry, Suez Canal University.

3- Assistant Professor, Department of Oral and Maxillofacial Surgery, Faculty of Dentistry, Suez Canal University.

4- Lecturer of Orthodontics, Department of orthodontics, Faculty of Dentistry, Suez Canal University.

5- Professor, Department of Orthodontics, Faculty of Dentistry, Suez Canal University. 
Egyptian

Orthodontic Journal

\section{INTRODUCTION}

Lengthy orthodontic treatment time has been linked to an increased risk of root resorption, gingival inflammation, decalcification, and dental caries. Therefore, reducing the treatment time is an appropriate goal, which requires increasing the rate of tooth movement. One of the possible methods for completing treatment in a shorter period is through an orthodontic treatment combined with corticotomy. A corticotomy is defined as any intentional surgical injury to cortical bone.

Anchorage loss often produces insufficient treatment results, particularly in patients who require maximum anchorage. With the introduction of mini-plates, micro-implants and mini-screws as anchorage, it has become possible to achieve absolute anchorage. Therefore, an orthodontic treatment combined with corticotomy and placement of mini-implants may provide the advantage of shortening the orthodontic treatment period in maximum anchorage cases. However, there have been few case reports in which such a therapy was performed.

Köle ${ }^{1}$ introduced a corticotomy technique to enable movement of a bone segment that includes a tooth by sectioning the layer of compact bone. This technique involved a radicular corticotomy and supra-apical osteotomy. Suya ${ }^{2}$ suggested modification to the osteotomy cuts with horizontal corticotomy.

Duker ${ }^{3}$ investigated that Rearrangement of the teeth within a short time after corticotomy damaged neither the pulp nor the periodontal ligament (PDL). He supported the idea of preserving the marginal crest bone in relation to interdental cuts; these cuts must always be left at least $2 \mathrm{~mm}$ short of the alveolar crestal bone level. Gantes et al ${ }^{4}$ presented five orthodontic cases treated with corticotomy in which they performed circumscribing corticotomy cuts both facially and lingually around the six upper anterior teeth. Wilcko et al ${ }^{5}$ described an innovative strategy of combining corticotomy surgery with alveolar grafting in a technique referred to as Accelerated Osteogenic Orthodontics (AOO). They demonstrated this surgical technique through two cases. 
Germec et $\mathrm{al}^{6}$ claimed a significant reduction in treatment time, with no adverse effects on the periodontium or tooth vitality, when they used modified corticotomy to retract protrusive mandibular incisors. Iino et al ${ }^{7}$ used corticotomies to treat an adult bimaxillary protrusion patient with placement of titanium miniplates and the treatment only lasted for a year.

Corticotomy procedures have been shown also to speed up the intrusion of supraerupted teeth. ${ }^{8-11}$ Corticotomies have also been used to facilitate molar distalization and arch expansion. Spena et $\mathrm{al}^{12}$ distalized molars into a Class I relationship in 8 weeks. Hassan et $\mathrm{al}^{13}$ used corticotomy to speed up expansion of two adults with true unilateral posterior crossbites. The aim of this study was to evaluate effect and duration of labial corticotomy compared with palatal corticotomy assisted en masses retraction using miniscrews as anchorage.

\section{MATERIALS AND METHODS}

The sample consisted of twenty female patients aged 18 to 27 years old. Criteria of selection included: patients with maxillary or bimaxillary protrusion, healthy systemic condition, no previous orthodontic treatment, adequate oral hygiene, No congenitally missing teeth. The patients were divided into:

\section{Group 1 (G1) subjects:}

10 patients treated with mini screw dependent en masse retraction associated with labial corticotomy facilitated technique.

\section{Group 2 (G2) subjects:}

10 patients treated with mini screw dependent en masse retraction associated with palatal corticotomy facilitated technique.

Corticotomy, was explained to the subjects and a signed informed consent obtained. For all subjects, the following records were evaluated: dental casts photographs and panaromic and cephalometric radiograph before and after treatment 
Egyptian

Orthodontic Journal

After placement of maxillary and mandibular fixed orthodontic appliances (Preadjusted edgewise appliance system, Roth prescription, slot size 0.022 x 0.028 inch, Mini Diamond, Ormco, Glendora, Calif) and completion of the levelling and alignment phase of treatment, miniscrew implants (AbsoAnchor, Dentos, Daegu, Korea; diameter, $1.3 \mathrm{~mm}$; length, $8 \mathrm{~mm}$ ), used as skeletal anchor units, were placed bilaterally between the maxillary second premolar and the first molar. When $0.018 \times 0.025$ inch. St.St maxillary arch wire was inserted, crimpable hooks were placed distal to the lateral incisor and the patients referred for extraction and corticotomy.

\section{Surgical procedure:}

Corticotomy surgery was performed in the maxillary alveolar region from mesial surface of maxillary 1st premolar of one side to the other side. Surgery was performed under local anaesthesia. A full thickness periosteal flap was raised only on the labial side or palatal side of the cortical bone. Vertical grooves were placed in the interradicular space, midway between the root prominences in the alveolar bone. The grooves were made to extend from 1 to $3 \mathrm{~mm}$ below the alveolar crest of the bone and were extended $2 \mathrm{~mm}$ beyond the apices of the roots. Horizontal corticotomy cuts were made, joining these vertical cuts (figure 1). BioGen cortical granules (Bioteck S.p.A., Via E. Fermi 49, 36057 Arcugnano (Vicenza), Italy) as bone graft material were mixed with saline and placed over areas that have undergone corticotomies (figure 2). After the completion of surgery, sutures were given after placing the raised flap back. All the patients were given post-operative antibiotics and anti-inflammatory agents 5 days following the surgery.
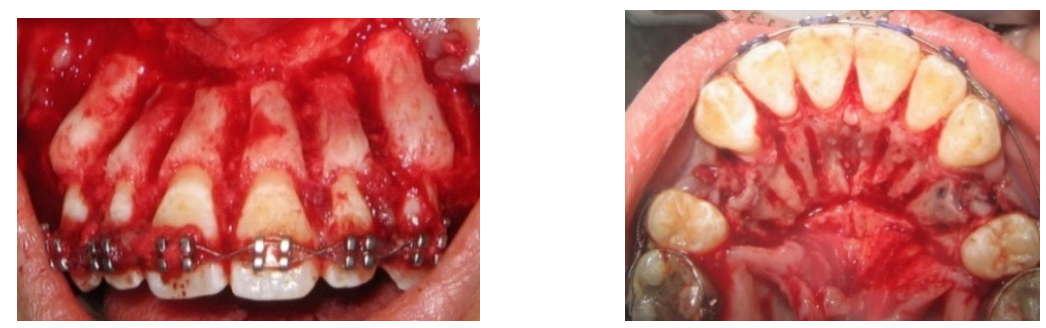

Figure (1): Interradicular corticotomy cuts on labial or palatal side of the cortical bone

Volume 47 - June 2015 

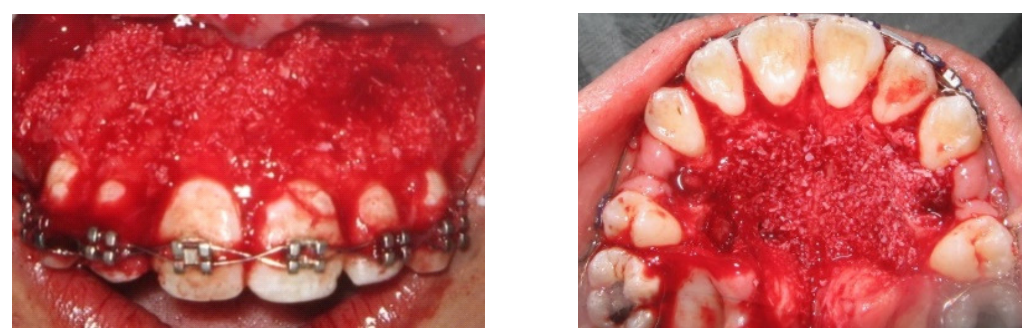

Figure (2): Bone graft placement

Patients were recalled within a week for placement of arch wire to start the retraction of maxillary anterior segment and to maximize the effects of corticotomy for orthodontic tooth movement. Power chains were used to close the extraction spaces and en masse retraction of the six maxillary anterior teeth from the mini screw to the crimpable hook on the arch wire (figure 3). Power chains were replaced every 2 weeks.

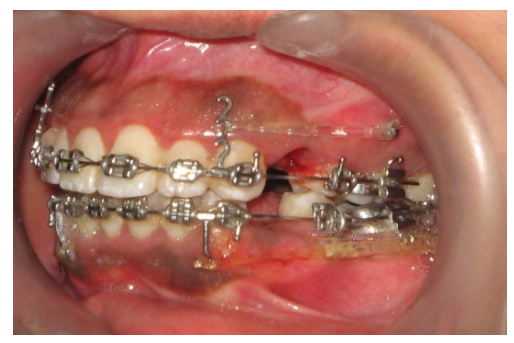

Figure (3): Application of retraction force by power chain

Time taken for complete space closure was recorded from the day of application of the en masse retraction force to end of the space closure. Lateral cephalograms at pretreatment (T1) and after treatment (T2) were used for cephalometric analysis.

\section{Statistical analysis}

Statistical analysis was carried out using SPSS program (SPSS, 2008). The mean and standard deviation for the variables were calculated. Pre-treatment to post-treatment changes for each variable were analysed. Paired t-test was also used to evaluate the treatment difference between group 1 and group 2 . 
Egyptian

Orthodontic Journal

\section{RESULTS}

There was no significant difference at $(p \geq 0.05)$ between $G 1$ and G2 in the mean of en masse retraction time (Table 1 and fig. 4). There was a statistically significant difference in the SNA angle within each group (Table 2 ). Highly significant difference at $(p \leq 0.001)$ was observed form dental angular and linear measurement for the effect of treatment (before-after). There was significant increase in U1-L1 angle while there was significant decrease in U1-NA and U1-FH angles. Also there was significant decrease in U1-NA ( $\mathrm{mm}$ ) linear measurement as shown in (Table 3). While; there was no significant difference between the two groups in both skeletal and dental changes.

Table 1: comparison of retraction time in the two groups (months) by t-test

\begin{tabular}{|c|c|c|c|c|}
\hline Variable & Group & Mean & S.D & p-value \\
\hline \multirow{2}{*}{ Retraction time } & Group 1 & 7.64 & 0.668 & $\geq 0.05$ \\
\cline { 2 - 4 } & Group 2 & 7.48 & 0.538 & \\
\hline
\end{tabular}

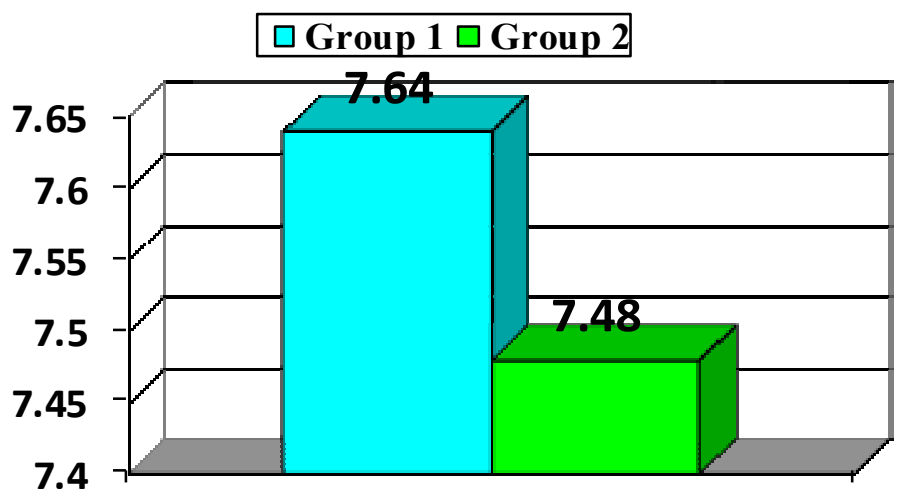

Fig. (4): Mean duration of retraction (in months) in the two groups 


\section{Egyptian}

Orthodontic Journal

Table 2: Comparison of pretreatment and posttreatment skeletal changes (T2-T1) between groups

\begin{tabular}{|c|c|c|c|c|c|c|c|c|c|}
\hline \multirow{2}{*}{ Treatment } & \multirow{2}{*}{ Measurement } & \multicolumn{2}{|c|}{ Before } & \multicolumn{2}{|c|}{ After } & \multirow{2}{*}{$\begin{array}{c}\text { Mean } \\
\text { Diff. }\end{array}$} & \multirow{2}{*}{$\begin{array}{l}\text { S.E. } \\
\text { Diff. }\end{array}$} & \multirow{2}{*}{ t value } & \multirow{2}{*}{$P$} \\
\hline & & Mean & S.D. & Mean & S.D. & & & & \\
\hline \multirow{4}{*}{ Group 1} & SNA & 81.30 & 1.947 & 79.80 & 2.300 & -1.500 & 0.477 & -3.143 & $0.012 *$ \\
\hline & SNB & 75.30 & 2.669 & 74.30 & 2.058 & -1.000 & 0.258 & -3.873 & $0.004 * *$ \\
\hline & ANB & 6.00 & 2.828 & 5.50 & 3.274 & -0.500 & 0.373 & -1.342 & $0.213 \mathrm{NS}$ \\
\hline & N-A-Pog & 12.20 & 5.432 & 10.20 & 6.828 & -2.000 & 0.730 & -2.739 & $0.023 *$ \\
\hline \multirow{4}{*}{ Group 2} & SNA & 84.40 & 3.064 & 82.70 & 2.486 & -1.700 & 0.300 & -5.667 & $0.001 * * *$ \\
\hline & SNB & 76.30 & 3.864 & 75.50 & 3.498 & -0.800 & 0.389 & -2.058 & $0.070 \mathrm{NS}$ \\
\hline & ANB & 8.10 & 3.302 & 7.20 & 3.028 & -0.900 & 0.314 & -2.862 & $0.019 *$ \\
\hline & N-A-Pog & 17.00 & 2.025 & 14.30 & 2.098 & -2.700 & 0.667 & -4.045 & $0.003 * *$ \\
\hline
\end{tabular}

Table 3: Comparison of pretreatment and posttreatment dental changes (T2-T1) between groups

\begin{tabular}{|c|c|c|c|c|c|c|c|c|c|}
\hline \multirow{2}{*}{ Treatment } & \multirow{2}{*}{ Measurement } & \multicolumn{2}{|c|}{ Before } & \multicolumn{2}{|c|}{ After } & \multirow{2}{*}{$\begin{array}{c}\text { Mean } \\
\text { Diff. }\end{array}$} & \multirow{2}{*}{$\begin{array}{l}\text { S.E. } \\
\text { Diff. }\end{array}$} & \multirow{2}{*}{ t value } & \multirow{2}{*}{$\mathbf{P}$} \\
\hline & & Mean & S.D. & Mean & S.D. & & & & \\
\hline \multirow{5}{*}{ Group 1} & U1-L1 ( $\left.{ }^{\circ}\right)$ & 111.0 & 4.397 & 137.6 & 6.240 & 26.6 & 2.050 & 12.973 & $0.001 * * *$ \\
\hline & U1-NA & 28.1 & 3.872 & 11.4 & 4.300 & -16.7 & 1.001 & -16.691 & $0.001 * * *$ \\
\hline & $\mathrm{U} 1-\mathrm{FH}\left(^{\circ}\right)$ & 115.8 & 2.044 & 97.9 & 5.820 & -17.9 & 1.595 & -11.224 & $0.001 * * *$ \\
\hline & U1-NA (1 & 8.7 & 1.767 & 2.3 & 1.829 & -6.4 & 0.702 & -9.112 & $0.001 * * *$ \\
\hline & U1-Ap & 14.8 & 2.700 & 6.6 & 1.350 & -8.2 & 0.629 & -13.038 & $0.001 * * *$ \\
\hline \multirow{5}{*}{ Group 2} & U1-L1 ( $\left.{ }^{\circ}\right)$ & 105.5 & 4.836 & 132.8 & 5.473 & 27.3 & 2.679 & 10.189 & $0.001 * * *$ \\
\hline & $\mathrm{U} 1-\mathrm{NA}\left({ }^{\circ}\right)$ & 24.4 & 9.058 & 8.6 & 4.789 & -15.8 & 2.394 & -6.601 & $0.001 * * *$ \\
\hline & U1-FH $\left({ }^{\circ}\right)$ & 115.6 & 7.763 & 97.9 & 7.400 & -17.7 & 1.955 & -9.052 & $0.001 * * *$ \\
\hline & U1-NA ( $\mathrm{n}$ & 7.8 & 2.201 & 1.7 & 1.160 & -6.1 & 0.605 & -10.089 & $0.001 * * *$ \\
\hline & U1-Apg (mm) & 16.1 & 2.514 & 7.3 & 1.889 & -8.8 & 0.646 & -13.615 & $0.001 * * *$ \\
\hline
\end{tabular}

S.D. $=$ Standard deviation

$\mathrm{P} \quad=$ Probability level for the effect of treatment (Paired $t$ teats).

NS $=$ Non significant $\mathrm{p}>0.05 \quad *=$ Significant at $\mathrm{p} \leq 0.05$

$* *=$ Significant at $\mathrm{p} \leq 0.01 \quad * * *=$ Significant at $\mathrm{p} \leq 0.001$ 
Egyptian

Orthodontic Journal

\section{DISCUSSION}

Reduction of orthodontic therapy time is considered to be an important goal in the management of malocclusion. Corticotomy has been proposed as an alternative to conventional orthodontic treatment in difficult adult cases for rapid tooth movement.

Generally, the conventional corticotomy techniques include both labial and lingual corticotomy cuts like the procedures described by Wilcko et $\mathrm{al}^{5}$, and Murphy et $\mathrm{al}^{14}$. In the current study the corticotomy cuts were performed on only labial side or palatal side of the cortical bone. This technique is in agreement with Germec et al ${ }^{6}$ who reported rapid tooth movement when corticotomy was performed at the buccal aspects of alveolar bone and Nowzari et al ${ }^{15}$ who performed only buccal mucoperiosteal flaps, and selected vertical and horizontal corticotomy cuts were performed around the roots in both the maxillary and mandibular arches.

The main purpose of this conservative, one stage surgery was to reduce the operation time and postoperative patient discomfort by eliminating exposure of the patient to the risks of both labial and palatal surgery. Elastic chain was used in this study to make immediate force application easier without discomfort for cases subjected to surgery and to facilitate proper oral hygiene and to avoid soft tissue impingement around the coil spring

The results of the present study are in accordance with the results of the study done by Wilcko et al ${ }^{5,16,17}$ in which the corticotomy procedure has reduced the treatment time.

The results of this study showed that no significant difference in the mean retraction time between $\mathrm{G} 1$ and $\mathrm{G} 2$, despite the difference in the corticotomy site. The mean retraction period was 7.64 months (229.30 days) and 7.48 months (224.30 days) for G1 and G2 respectively. These results were different from Bhattacharya et al ${ }^{33}$ who reported that the retraction time of the corticotomy group was 130.50 days (4.35 months). The same for Chung et $\mathrm{al}^{19}$ who demonstrated that the maxillary anterior retraction was completed in 5 months after peri-segmental lingual and labial corticotomy and c-palatal plate for 
Egyptian

Orthodontic Journal

anchorage with a retraction force of $500 \mathrm{~g}$ per side were used. This may be attributed to that the corticotomy in this study was performed only on one side of the cortical bone. While in their studies the lingual and labial corticotomies were performed.

The use of mini-screws in this study was necessary to retract the anterior teeth with absolute anchorage of maxillary molars in order to improve sever upper teeth protrusion. The results were found to be compatible with the results of Choo et al ${ }^{20}$ and Tizini and Ibrahim ${ }^{21}$ who demonstrated that there was a significant decrease in SNA angle. The results of this study also showed statistically significant $(\mathrm{P} \leq 0.001)$ levels of maxillary incisor retraction were achieved between the pre-treatment and post-treatment for both dental angular and linear.

In the present study the comparison between en-masse retractions with corticotomy on labial side only or palatal side only were selected because the labial side provides more accessibility during the surgery. Although palatal side less accessible, but the palatal cortical bone and width of the alveolar bone could be limiting factors in orthodontic retraction. Therefore palatal corticotomy may decrease the bone resistance to teeth movement toward palatal direction. As the results in this study have demonstrated that there was no significant difference in duration of retraction and even the effect of retraction between G1 (labial coticotomy) and G2 (palatal corticotomy). Therefore, the results of the present study suggest that labial corticotomy or palatal corticotomy can be used in conjunction with en-masse retraction of the maxillary anterior teeth to reduce the time of retraction. However, the accessible side of corticotomy can be used to provide good visualization.

\section{CONCLUSION}

The use of corticotomy technique from labial side only could be beneficial for adult patients with difficult surgical access from the palatal side. Reduction of surgery time and patient discomfort are basic advantages to a single side corticotomy. 
Egyptian

Orthodontic Journal

\section{REFERENCES}

1. Köle H. Surgical operations of the alveolar ridge to correct occlusal abnormalities. Oral Surg Oral Med Oral Pathol 1959; 12:515-29

2. Suya H. Corticotomy in orthodontics. In: Hosl, E., Baldauf, A. (Eds.), Mechanical and Biological Basis in Orthodontic Therapy. Huthig Buch Verlag, Heidelberg, Germany, 1991.p. 207-226.

3. Duker J. Experimental animal research into segmental alveolar movement after corticotomy. J Maxillofac Surg. 1975; 3: 81-84.

4. Gantes B, Rathbun E, Anholm M: Effects on the periodontium following corticotomy-facilitated orthodontics: case reports. J Periodontol. 1990; 61:234-238.

5. Wilcko WM, Wilcko T, Bouquot JE, Ferguson DJ. Rapid orthodontics with alveolar reshaping: two case reports of decrowding. Int J Periodontics Restorative Dent 2001; 21: 9-19.

6. Germec D, Giray B, Kocadereli I, Enacar A. Lower incisor retraction with a modified corticotomy. Angle Orthod 2006; 76:882-890.

7. Iino S, Sakoda S, Miyawaki S. An adult bimaxillary protrusion treated with corticotomy-facilitated orthodontics and titanium miniplates. Angle Orthod 2006; 76: 1074-1082.

8. Hwang HS, Lee KH: Intrusion of overerupted molars by corticotomy and magnets. Am J Orthod Dentofacial Orthop 120:209-216, 2001

9. Moon $\mathrm{CH}$, Wee JU, Lee HS: Intrusion of overerupted molars by corticotomy and orthodontic skeletal anchorage. Angle Orthod $77: 1119-1125,2007$

10. Oliveira DD, de Oliveira BF, de Araújo Brito HH, et al: Selective alveolar corticotomy to intrude overerupted molars. Am J Orthod Dentofacial Orthop 133:902-908, 2008

11. Kanno T, Mitsugi M, Furuki Y, et al: Corticotomy and compression osteogenesis in the posterior maxilla for treating severe anterior open bite. Int J Oral Maxillofac Surg 36:354-357, 2007 
12. Spena R, Caiazzo A, Gracco A, Siciliani G. The use of segmental corticotomy to enhance molar distalization. J Clin Orthod 2007; 41: 693-699.

13. Hassan AH, Al-Ghamdi AT, Al-Fraidi AA, Al-Hubail A. Unilateral cross bite treated by corticotomy-assisted expansion: two case reports. Head Face Med 2010, 6:6.

14. Murphy KG, wilcko TM, wilcko MW, ferguson DJ Periodontal Accelerated Osteogenic Orthodontics: A Description of the Surgical Technique. J Oral Maxillofac Surg. 2009; 67:2160-66.

15. Nowzari H, Yorita FK, Chang HC. Periodontally accelerated osteogenic orthodontics combined with autogenous bone grafting. Compend. Contin Educ Dent.2008; 29 (4):200-206.

16. Wilcko WM, Ferguson DJ, Bouquot JE, Wilcko MT. Rapid orthodontic decrowding with alveolar augmentation: Case Report. World J Orthod 2003; 4:197-205

17. Wilcko MT, Wilcko WM, Bissada NF. An evidence-based analysis of periodontally accelerated orthodontic and osteogenic techniques: a synthesis of scientific perspective. Semin Orthod. 2008; 14:305-316.

18. Bhattacharya $\mathrm{P}$, Bhattacharya H, Anjum A, Bhandari R, Agarwal D K, Gupta A, Ansar J. Assessment of Corticotomy Facilitated Tooth Movement and Changes in Alveolar Bone Thickness - A Ct Scan Study. J of Clin and Diagns Res. 2014; 8(10): 26-30.

19. Chung KR, Kim SH, Lee BS. Speedy surgical-orthodontic treatment with temporary anchorage devices as an alternative to orthognathic surgery. Am J Orthod Dentofacial Orthop 2009; 135:787-798.

20. Choo HR., Heo HA, Yoon HJ, Chung KR, Kim SH. Treatment outcome analysis of speedy surgical orthodontics for adults with maxillary protrusion. Am J Orthod Dentofacial Orthop 2011; 140:251-262.

21. Tizini $M$ and Ibrahim G. Retraction of the upper maxillary incisors with corticotomy-facilitated orthodontics and mini-implants. Saudi J Dent Res 2013; 1-6. 